\title{
Stereochemical effect of the small ring unit in 7-R-3,4-cyclopropano- and 7-R-3,4-epoxy- bicyclo[4.2.0]octan-1,5-dienes on conrotatory ring opening torquoselectivity
}

\author{
Veejendra K. Yadav \\ Department of Chemistry, Indian Institute of Technology Kanpur, Kanpur-208016, India \\ vijendra@iitk.ac.in
}

ABSTRACT. Application of the differential activation energy approach suggests that the strong inward opening tendency of the formyl group in 3,4-cyclopropano-7-formyl-bicyclo[4.2.0]octan-1,5-diene and also 3,4-epoxy-7-formyl-bicyclo[4.2.0]octan-1,5-diene is either counter balanced to a level that the reaction turns torquo-neutral or it rotates outward, depending upon the stereo-relationship of the small ring unit with the formyl substituent. The NBO interaction approach, however, predicts inward selectivity throughout. These molecules, therefore, can be used as excellent test examples to judge the validity of one approach over the other.

Keywords. Torquoselectivity, 7-R-3,4-cyclopropano-bicyclo[4.2.0]octan-1,5-diene, 7-R-3,4-epoxybicyclo[4.2.0]octan-1,5-diene, remote substituent effect, torquo-neutral, torquo-reversal

\section{INTRODUCTION}

The conrotatory ring opening of 7-carbomethoxy-bicyclo[4.20]octan-1,3,5-triene does not involve $\pi_{\mathrm{C1C6}}-\sigma^{*}{ }_{\mathrm{c7c8}}$ interaction as in the opening of 3-carbomethoxycyclobutene and that the reaction is an eight-electron process rather than the more common four-electron phenomenon encountered with simple 3-substituted cyclobutenes. ${ }^{1-3}$ An understanding of the operating orbital-orbital interactions in the transition state (TS) structure guided us to study the conrotatory opening of the four-membered ring in anti-7-carbomethoxy-3,4-cyclopropano-bicyclo[4.2.0]octan-1,5-diene, 1, and anti-7carbomethoxy-3,4-epoxy-bicyclo[4.2.0]octan-1,5-diene, 4. To study the effect of the remote small ring units on torquoselectivity. Having included the $\sigma_{\subset 3 c 4}$ and $\sigma_{C 7 C 8}$ electrons, both the substrates are geared for an eight-electron process to form seven-membered ring products as shown in Scheme 1.

The shown location of the three-membered ring was considered necessary to allow the relay of orbital-orbital interactions enroute the ring opening. The canted orbitals resident on C3 and C4 must guarantee their overlap with the adjacent $p$ orbitals to allow $\pi$ bond formation between C2 and C3, and $\mathrm{C} 4$ and $\mathrm{C} 5$ to form one or both the products. ${ }^{4}$ The products $\mathbf{2}$ and $\mathbf{5}$, and $\mathbf{3}$ and $\mathbf{6}$ are formed from, respectively, inward and outward openings. The reactions of the corresponding syn-derivatives, wherein the methylene of cyclopropane and oxygen of oxirane are oriented syn to the ester group, were also studied to explore whether this stereochemical change in the substrate had any bearing on 
the torquoselectivity of ring opening. The corresponding 7-formyl species were also studied to estimate the effects of the small ring units on its strong inward opening tendency. ${ }^{3,5}$
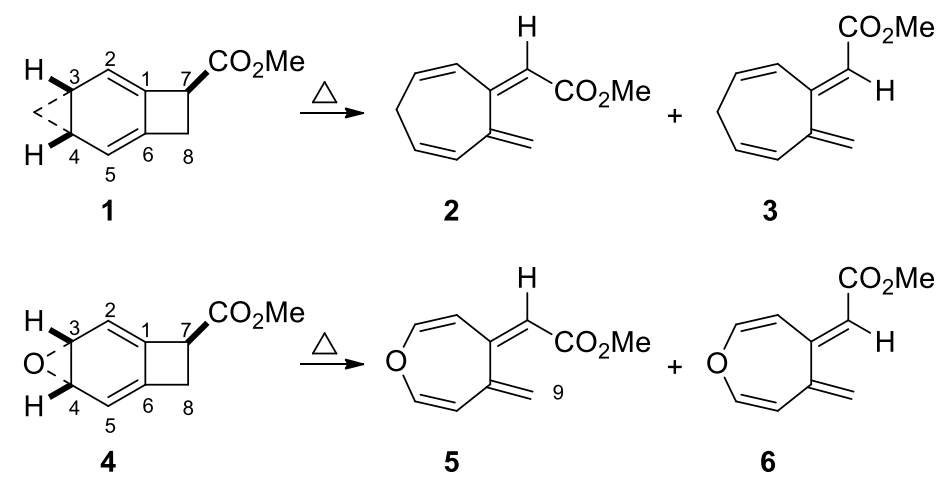

Scheme 1. Conrotatory ring opening reactions of $\mathbf{1}$ and $\mathbf{4}$

We report herein the results from density functional calculations and demonstrate that the conrotatory ring opening in each instance is clearly an eight-electron process as the orbital interaction characteristic of the four-electron process is completely absent.

\section{Computational methods}

For all the structures, geometry optimizations and TS structure searches were carried out at $298.15 \mathrm{~K}$ under $1 \mathrm{~atm}$ pressure using the hybrid meta-GGA M06-2X density functional and $6-31+G(d, p)$ basis set. ${ }^{6}$ The optimized structures were verified as minima or first order saddle points by harmonic vibrational frequency analysis. In order to understand the strengths of the participating frontier orbital interactions, the natural bond orbital (NBO) analysis was conducted using the NBO program. ${ }^{7}$ Calculations were carried out using the Gaussian 09 suite of programs. ${ }^{8}$ All the energies reported herein are Gibbs free energies (sum of Electronic and Thermal Free Energies) in kcal/mol.

\section{RESULTS AND DISCUSSION}

The activation barriers and important NBO interactions for the inward and outward openings of $\mathbf{1}$ are collected in Table 1 . The $1.0 \mathrm{kcal} / \mathrm{mol}$ difference in the activation energies predicts approximately 80:20 mixture predominating in outward opening. Since the inward and outward opening reactions are exothermic by 3.3 and $6.8 \mathrm{kcal} / \mathrm{mol}$, respectively, no equilibration through reversal is expected under mild reaction conditions. The torquoselectivity determining $\sigma_{\mathrm{c} 7 c 8} \rightarrow \pi^{*} \mathrm{c=0}$ interaction, however, argues otherwise as it favors inward opening predominantly. The said interaction in inward opening TS structure is $21.6 \mathrm{kcal} / \mathrm{mol}$ larger than in outward opening. 
Table 1. Gibbs' free energy of activation $\left(\triangle \mathrm{G}^{\ddagger}\right)$ and important NBO interaction energies (kcal/mol) for the inward and outward ring openings of anti-7-carbomethoxy-3,4-cyclopropano-bicyclo[4.2.0]octan-1,5-diene, 1

\begin{tabular}{|l|l|l|l|l|l|l|}
\hline TS & $\triangle \mathrm{G}^{\ddagger}$ & $\pi \mathrm{C} 1 \mathrm{C6} \rightarrow \sigma^{*} \mathrm{C7C8}$ & $\sigma \mathrm{c7C8} \rightarrow \pi^{*}{ }_{\mathrm{C} 1 \mathrm{C} 6}$ & $\sigma \mathrm{c7C8} \rightarrow \pi^{*} \mathrm{c}=0$ & $\pi \mathrm{C}=0 \rightarrow \sigma^{*}{ }_{\mathrm{C} 7 \mathrm{C} 8}$ & $\mathrm{G}_{2 / 3}-\mathrm{G}_{1}$ \\
\hline inward & 30.6 & 48.7 & 55.8 & 46.3 & 1.4 & -3.3 \\
\hline outward & 29.6 & 45.5 & 51.7 & 24.7 & 4.8 & -6.8 \\
\hline
\end{tabular}

Table 2. Gibbs' free energy of activation $\left(\triangle \mathrm{G}^{\ddagger}\right)$ and important NBO interaction energies $(\mathrm{kcal} / \mathrm{mol})$ for the inward and outward ring openings of anti-7-carbomethoxy-3,4-epoxy-bicyclo[4.2.0]octan-1,5-diene, 4

\begin{tabular}{|l|l|l|l|l|l|l|}
\hline TS & $\triangle \mathrm{G}^{\ddagger}$ & $\pi_{\mathrm{C} 1 \mathrm{C6} \rightarrow} \rightarrow \sigma^{*}{ }_{\mathrm{C} 7 \mathrm{C} 8}$ & $\sigma_{\mathrm{C} 7 \mathrm{C} 8} \rightarrow \pi^{*}{ }_{\mathrm{C} 1 \mathrm{C6}}$ & $\sigma_{\mathrm{C} 7 \mathrm{C8} \rightarrow \pi^{*} \mathrm{C}=\mathrm{O}}$ & $\pi_{\mathrm{C}=0} \rightarrow \sigma^{*}{ }_{\mathrm{C} 7 \mathrm{C} 8}$ & $\mathrm{G}_{5 / 6}-\mathrm{G}_{4}$ \\
\hline inward & 34.4 & 44.5 & 51.0 & 45.1 & 0.8 & -07.0 \\
\hline outward & 33.2 & 41.6 & 47.7 & 23.7 & 4.8 & -10.9 \\
\hline
\end{tabular}

A similar argument is applicable to the opening of the epoxy species 4. From the data in Table 2, the outward opening is favored over inward opening by a margin of $1.2 \mathrm{kcal} / \mathrm{mol}$ from a consideration of activation energies. This activation energy difference corresponds to approximately 9:1 kinetic distribution in favor of outward opening. Here also, the inward opening is supported by $\sigma_{\mathrm{c} 7 \mathrm{c} 8} \rightarrow \pi_{\mathrm{c}=0}^{*}$ interaction, which is much the same as in the opening of the cyclopropyl species 1.

Three interesting observations emerge from the above discussions. (a) The activation barrier for ring opening in 4 is $3.6-3.8 \mathrm{kcal} / \mathrm{mol}$ higher than 1 . This may be due to less strain in oxirane than cyclopropane and/or relatively inferior alignment of the canted orbitals with the adjacent $p$ orbitals in the oxirane than cyclopropane..$^{9}$ (b) In comparison to the activation barriers for inward and outward openings of 7-carbomethoxy-bicyclo[4.2.0]octan-1,3,5-triene that are, respectively, 42.9 and 40.6 $\mathrm{kcal} / \mathrm{mol}$ strong, the activation barriers for the openings of both 1 and $\mathbf{4}$ are considerably reduced. This may be due to the larger energy requirement for disrupting the ring aromaticity. (c) Though eightelectron process, the diastereoselectivity controlling $\sigma_{\mathrm{C7C8}} \rightarrow \pi^{*}{ }_{\mathrm{C}=0}$ and $\pi_{\mathrm{C}=0} \rightarrow \sigma^{*}{ }_{\mathrm{C7C8}}$ interactions are present in the openings of both $\mathbf{1}$ and $\mathbf{4}$, which is absent in the reactions of 7-carbomethoxybicyclo[4.2.0]octan-1,3,5-triene.

Other significant NBO interactions are collected in Tables 3 and 4 for the reactions of $\mathbf{1}$ and $\mathbf{4}$, respectively. Some features are notable. First, a good $\pi$ character develops between $\mathrm{C} 1$ and $\mathrm{C} 6$ as this bond length is decreased from $1.45 \AA$ in the ground state structures to 1.40 and $1.39 \AA$ in both the TS structures for 1 and 4, respectively. Second, $\pi$ character develops between $C 2$ and $C 3$, and $C 4$ and $C 5$, and they both interact reasonably well with the developing $\pi$ bond between $\mathrm{C} 1$ and $\mathrm{C} 6$. Third, and the 
most surprising, the originally anticipated overlap of $\sigma_{\mathrm{c}_{3} 4}$ bond with the adjacent $\pi$ bonds $\pi_{\mathrm{C} 1 \mathrm{C}_{2}}$ and $\pi_{\mathrm{csc6}}$ is completely absent.

Table 3. Other significant NBO interactions ( $\mathrm{kcal} / \mathrm{mol})$ present in the inward and outward opening TSs of anti-7carbomethoxy-3,4-cyclopropanobicyclo[4.2.0]octan-1,5-diene, 1

\begin{tabular}{|l|l|l|l|l|l|l|}
\hline TS & $\pi_{\mathrm{C} 1 \mathrm{C} 2} \rightarrow \sigma^{*}{ }_{\mathrm{C} 3 \mathrm{C} 4}$ & $\pi_{\mathrm{C} 5 \mathrm{C} 6} \rightarrow \sigma^{*}{ }_{\mathrm{C} 3 \mathrm{C} 4}$ & $\pi_{\mathrm{C} 1 \mathrm{C} 6} \rightarrow \pi_{\mathrm{C} 2 \mathrm{C} 3}^{*}$ & $\pi_{\mathrm{C} 2 \mathrm{C} 3} \rightarrow \pi_{\mathrm{C} 1 \mathrm{C} 6}$ & $\pi_{\mathrm{C} 1 \mathrm{C} 6} \rightarrow \pi_{\mathrm{C} 4 \mathrm{C} 5}$ & $\pi_{\mathrm{C} 4 \mathrm{C} 5} \rightarrow \pi_{\mathrm{C} 1 \mathrm{C} 6}$ \\
\hline inward & 0.0 & 0.0 & 14.4 & 17.3 & 12.7 & 09.4 \\
\hline outward & 0.0 & 0.0 & 12.2 & 10.2 & 14.4 & 16.1 \\
\hline
\end{tabular}

Table 4. Other significant NBO interactions ( $\mathrm{kcal} / \mathrm{mol}$ ) present in the inward and outward opening TSs of anti-7carbomethoxy-3,4-epoxybicyclo[4.2.0]octan-1,5-diene, 4

\begin{tabular}{|l|l|l|l|l|l|l|}
\hline TS & $\pi_{\mathrm{C} 1 \mathrm{C} 2} \rightarrow \sigma^{*}{ }_{\mathrm{C} 3 \mathrm{C} 4}$ & $\pi_{\mathrm{C} 5 \mathrm{C} 6} \rightarrow \sigma_{\mathrm{C} 3 \mathrm{C} 4}$ & $\pi_{\mathrm{C} 1 \mathrm{C} 6} \rightarrow \pi_{\mathrm{C} 2 \mathrm{C} 3}$ & $\pi_{\mathrm{C} 2 \mathrm{C} 3} \rightarrow \pi_{\mathrm{C} 1 \mathrm{C} 6}$ & $\pi_{\mathrm{C} 1 \mathrm{C} 6} \rightarrow \pi_{\mathrm{C} 4 \mathrm{C} 5}$ & $\pi_{\mathrm{C} 4 \mathrm{C} 5} \rightarrow \pi_{\mathrm{C} 1 \mathrm{C} 6}$ \\
\hline inward & 0.0 & 0.0 & 14.0 & 16.1 & 12.6 & 08.5 \\
\hline outward & 0.0 & 0.0 & 11.8 & 09.3 & 13.8 & 14.9 \\
\hline
\end{tabular}

The observations with syn-7-carbomethoxy-3,4-cyclopropano-bicyclo[4.2.0]octan-1,5-diene 7 and syn-7-carbomethoxy-3,4-epoxy-bicyclo[4.2.0]octan-1,5-diene 8 parallel the observations with the corresponding anti species discussed above. It is clear from the TS structure data in Tables 5 and 6 that these substrates also prefer outward opening. The differential activation energy for ring opening in $\mathbf{8}$ is the same as for $\mathbf{4}$ and larger for $\mathbf{7}(2.1 \mathrm{kcal} / \mathrm{mol})$ than $\mathbf{1}(1.0 \mathrm{kcal} / \mathrm{mol})$. This translates into same selectivity for $\mathbf{8}$ and $\mathbf{4}$, but superior selectivity for $\mathbf{7}$ over $\mathbf{1}$. To the best of our knowledge, such a distant stereochemical effect on torquoselectivity has not been studied before. From $\sigma_{\mathrm{C} 7 \mathrm{C} 8} \rightarrow \pi^{*}{ }_{\mathrm{c}=0}$ and $\pi_{\mathrm{C}=0} \rightarrow \sigma^{*}{ }_{\text {c7c8 }}$ interactions data, $\mathbf{7}$ and $\mathbf{8}$ are also inward selective.

Table 5. Gibbs' free energy of activation $\left(\triangle \mathrm{G}^{\ddagger}\right)$ and important NBO interaction energies (kcal/mol) for the inward and outward ring openings of syn-7-carbomethoxy-3,4-cyclopropano-bicyclo[4.2.0]octan-1,5-diene, 7
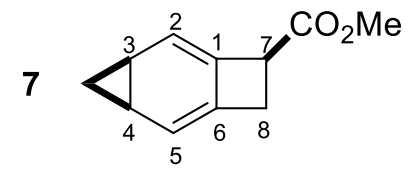

\begin{tabular}{|l|l|l|l|l|l|l|}
\hline TS & $\triangle \mathrm{G}^{\ddagger}$ & $\pi_{\mathrm{C} 1 \mathrm{C6} \rightarrow} \rightarrow \sigma^{*}{ }_{\mathrm{C} 7 \mathrm{C} 8}$ & $\sigma_{\mathrm{C} 7 \mathrm{C} 8} \rightarrow \pi^{*}{ }_{\mathrm{C} 1 \mathrm{C} 6}$ & $\sigma_{\mathrm{C} 7 \mathrm{C8} \rightarrow \pi^{*} \mathrm{C}=\mathrm{O}}$ & $\pi_{\mathrm{C}=\mathrm{O} \rightarrow \sigma^{*}{ }_{\mathrm{C} 7 \mathrm{C} 8}}$ & $\mathrm{G}_{2 / 3}-\mathrm{G}_{1}$ \\
\hline inward & 31.0 & 49.1 & 56.6 & 45.9 & 1.4 & -3.7 \\
\hline outward & 28.9 & 44.5 & 49.7 & 24.5 & 4.8 & -5.9 \\
\hline
\end{tabular}


Table 6. Gibbs' free energy of activation $\left(\Delta \mathrm{G}^{\ddagger}\right)$ and important NBO interaction energies $(\mathrm{kcal} / \mathrm{mol})$ for the inward and outward ring openings of syn-7-carbomethoxy-3,4-epoxy-bicyclo[4.2.0]octan-1,5-diene, 8

8

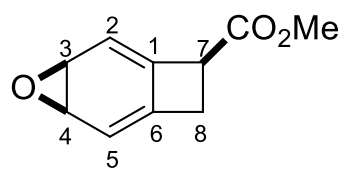

\begin{tabular}{|l|l|l|l|l|l|l|}
\hline TS & $\triangle \mathrm{G}^{\ddagger}$ & $\pi_{\mathrm{C} 1 \mathrm{C6} \rightarrow} \rightarrow \sigma^{*}{ }_{\mathrm{C} 7 \mathrm{C} 8}$ & $\sigma_{\mathrm{C} 7 \mathrm{C8} \rightarrow} \rightarrow \pi^{*}{ }_{\mathrm{C} 1 \mathrm{C6}}$ & $\sigma_{\mathrm{C} 7 \mathrm{C8} \rightarrow \pi^{*} \mathrm{c}=0}$ & $\pi_{\mathrm{C}=0} \rightarrow \sigma^{*}{ }_{\mathrm{C} 7 \mathrm{C} 8}$ & $\mathrm{G}_{5 / 6}-\mathrm{G}_{4}$ \\
\hline inward & 35.4 & 43.4 & 50.1 & 43.2 & 0.9 & -07.0 \\
\hline outward & 33.2 & 40.6 & 46.2 & 23.3 & 4.7 & -08.6 \\
\hline
\end{tabular}

The other NBO interactions in the TS structures for the openings of $\mathbf{7}$ and $\mathbf{8}$ are collected in Tables $\mathbf{7}$ and 8 , respectively. These interactions are similar to those in the TS structures for $\mathbf{1}$ and $\mathbf{4}$. The development of a good $\pi$ character between $\mathrm{C} 1$ and $\mathrm{C} 6, \mathrm{C} 2$ and $\mathrm{C} 3$, and $\mathrm{C} 4$ and $\mathrm{C} 5$ must be noted. The mutual interactions of these developing $\pi$ bonds are sufficiently strong. Also, the sum of the interactions $\pi_{\mathrm{C} 1 \mathrm{C} 6} \rightarrow \pi^{*}{ }_{\mathrm{C} 2 \mathrm{C} 3}$ and $\pi_{\mathrm{C} 2 \mathrm{C} 3} \rightarrow \pi^{*}{ }_{\mathrm{C} 1 \mathrm{C} 6} \mathrm{VS} \pi_{\mathrm{C} 1 \mathrm{C} 6} \rightarrow \pi^{*}{ }_{\mathrm{C} 4 \mathrm{C} 5}$ and $\pi_{\mathrm{C} 4 \mathrm{C} 5} \rightarrow \pi^{*}{ }_{\mathrm{C} 1 \mathrm{C} 6}$ switch over between the anti and syn species, i.e., if the sum of $\pi_{\mathrm{C} 1 \mathrm{C} 6} \rightarrow \pi^{*}{ }_{\mathrm{c} 2 \mathrm{C} 3}$ and $\pi_{\mathrm{C} 2 \mathrm{C} 3} \rightarrow \pi^{*}{ }_{\mathrm{c} 1 \mathrm{C} 6}$ interactions is larger than the sum of $\pi_{\mathrm{C} 1 \mathrm{C} 6} \rightarrow \pi^{*}{ }_{\mathrm{C} 4 \mathrm{C} 5}$ and $\pi_{\mathrm{C} 4 \mathrm{C} 5} \rightarrow \pi^{*}{ }_{\mathrm{C} 1 \mathrm{C} 6}$ interactions in the anti-isomer, it will be lower in the syn-isomer, and vice versa.

Table 7. Other significant NBO interactions $(\mathrm{kcal} / \mathrm{mol})$ present in the inward and outward opening TS structures of syn-7-carbomethoxy-3,4-cyclopropanobicyclo[4.2.0]octan-1,5-diene, 7

\begin{tabular}{|l|l|l|l|l|l|l|}
\hline TS & $\pi_{\mathrm{C} 1 \mathrm{C} 2} \rightarrow \sigma^{*}{ }_{\mathrm{C} 3 \mathrm{C} 4}$ & $\pi_{\mathrm{C} 5 \mathrm{C} 6} \rightarrow \sigma^{*}{ }_{\mathrm{C} 3 \mathrm{C} 4}$ & $\pi_{\mathrm{C} 1 \mathrm{C} 6} \rightarrow \pi^{*}{ }_{\mathrm{C} 2 \mathrm{C} 3}$ & $\pi_{\mathrm{C} 2 \mathrm{C} 3} \rightarrow \pi^{*}{ }_{\mathrm{C} 1 \mathrm{C} 6}$ & $\pi_{\mathrm{C} 1 \mathrm{C} 6} \rightarrow \pi^{*}{ }_{\mathrm{C} 4 \mathrm{C} 5}$ & $\pi_{\mathrm{C} 4 \mathrm{C} 5} \rightarrow \pi^{*}{ }_{\mathrm{C} 1 \mathrm{C} 6}$ \\
\hline inward & 0.0 & 0.0 & 12.4 & 09.5 & 13.4 & 16.8 \\
\hline outward & 0.0 & 0.0 & 13.9 & 18.1 & 13.6 & 09.7 \\
\hline
\end{tabular}

Table 8. Other significant NBO interactions $(\mathrm{kcal} / \mathrm{mol})$ present in the inward and outward opening TS structures of syn-7-carbomethoxy-3,4-epoxy-bicyclo[4.2.0]octan-1,5-diene, 8

\begin{tabular}{|l|l|l|l|l|l|l|}
\hline TS & $\pi_{\mathrm{C} 1 \mathrm{C} 2} \rightarrow \sigma^{*}{ }_{\mathrm{C} 3 \mathrm{C} 4}$ & $\pi_{\mathrm{C} 5 \mathrm{C} 6} \rightarrow \sigma^{*}{ }_{\mathrm{C} 3 \mathrm{C} 4}$ & $\pi_{\mathrm{C} 1 \mathrm{C} 6} \rightarrow \pi_{\mathrm{C} 2 \mathrm{C} 3}$ & $\pi_{\mathrm{C} 2 \mathrm{C} 3} \rightarrow \pi_{\mathrm{C} 1 \mathrm{C} 6}$ & $\pi_{\mathrm{C} 1 \mathrm{C} 6} \rightarrow \pi_{\mathrm{C} 4 \mathrm{C} 5}$ & $\pi_{\mathrm{C} 4 \mathrm{C} 5} \rightarrow \pi_{\mathrm{C} 1 \mathrm{C} 6}$ \\
\hline inward & 0.0 & 0.0 & 12.4 & 09.1 & 12.9 & 15.5 \\
\hline outward & 0.0 & 0.0 & 13.5 & 16.7 & 13.4 & 08.8 \\
\hline
\end{tabular}

Thus, whether the cyclopropyl or oxirane ring is anti or syn to the ester group, the differential activation energy supports outward opening in contrast to the torquoselectivity-controlling $\sigma_{\mathrm{C7C8}} \rightarrow \pi_{\mathrm{C}=\mathrm{O}}$ and $\pi_{\mathrm{C}=\mathrm{O}} \rightarrow \sigma^{*}{ }_{\mathrm{C} 7 \mathrm{C} 8}$ interactions that support inward opening. In a casual decision, we switched to study the reactions of anti-7-formyl-3,4-cyclopropano-bicyclo[4.2.0]octan-1,5-diene 9 and syn-7-formyl-3,4-cyclopropano-bicyclo[4.2.0]octan-1,5-diene 10 only because the formyl group is known 
to rotate almost exclusively inward during the conrotatory opening of 3 -formyl-cyclobutene. ${ }^{5}$ The activation barriers and important NBO interactions for the inward and outward openings of 9 and $\mathbf{1 0}$ are collected in Tables 9 and 10, respectively. A close inspection of the data in these tables reveals the followings:

(a) Differential activation energy predicts the anti-species 9 to be torquo-neutral for the merely 0.2 $\mathrm{kcal} / \mathrm{mol}$ difference. The syn-species $\mathbf{1 0}$, however, is predicted for largely outward opening for the $1.1 \mathrm{kcal} / \mathrm{mol}$ difference in its favor. The electronic effect conferred by the cyclopropane ring in $\mathbf{9}$ counterbalances the electronic effect of the formyl group to make it torquo-neutral. In 10, the cyclopropane ring reverses the inward torquoselectivity trend normally exhibited by the formyl group. These are the first reports on strong stereochemical effects of remote small ring systems on torquoselectivity.

(b) The torquo-controlling $\sigma_{\mathrm{c} 7 c 8} \rightarrow \pi_{\mathrm{c}=0}^{*}$ and $\pi_{\mathrm{c}=0} \rightarrow \sigma^{*}{ }_{\mathrm{c} 7 \mathrm{c} 8}$ interactions predict inward selectivity irrespective of the anti or syn disposition of the cyclopropane ring. These substrates therefore constitute good test cases to distinguish between the differential activation energy and NBO based approaches to torquoselectivity.

Table 9. Gibbs' free energy of activation $\left(\Delta \mathrm{G}^{\ddagger}\right)$ and important NBO interactions $(\mathrm{kcal} / \mathrm{mol})$ for the inward and outward openings of anti-7-formyl-3,4-cyclopropano-bicyclo[4.2.0]octan-1,5-diene, 9

9

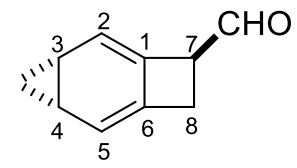

\begin{tabular}{|c|c|c|c|c|c|c|}
\hline TS & $\Delta G^{\ddagger}$ & $\pi_{\mathrm{C} 1 \mathrm{C} 6} \rightarrow \sigma^{*} \mathrm{ClC8}$ & $\sigma_{\mathrm{C} 7 \mathrm{CB}} \rightarrow \pi^{*}{ }_{\mathrm{C} 1 \mathrm{C} 6}$ & $\sigma_{\mathrm{C} 7 \mathrm{C} 8} \rightarrow \pi^{*} \mathrm{c}=\mathrm{O}$ & $\pi_{\mathrm{C}=0} \rightarrow \sigma^{*}{ }_{\mathrm{C} 7 \mathrm{C} 8}$ & $\mathrm{G}_{2 / 3}-\mathrm{G}_{1}$ \\
\hline inward & 28.9 & 49.4 & 54.0 & 40.8 & 1.3 & -3.6 \\
\hline outward & 29.1 & 44.1 & 49.7 & 23.4 & 6.5 & -6.8 \\
\hline
\end{tabular}

Table 10. Gibbs' free energy of activation $\left(\triangle \mathrm{G}^{\ddagger}\right)$ and important NBO interactions $(\mathrm{kcal} / \mathrm{mol})$ for the inward and outward openings of syn-7-formyl-3,4-cyclopropano-bicyclo[4.2.0]octan-1,5-diene, 10

10

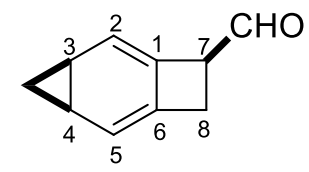

\begin{tabular}{|c|c|c|c|c|c|c|}
\hline TS & $\Delta G^{\ddagger}$ & $\pi \mathrm{c} 1 \mathrm{C} 6 \rightarrow \sigma^{*} \mathrm{C}_{\mathrm{C} C 8}$ & $\sigma \mathrm{C} 7 \mathrm{CB} \rightarrow \pi^{*} \mathrm{C}_{\mathrm{CC}}$ & $\sigma c 7 C 8 \rightarrow \pi^{*} \mathrm{c}=0$ & $\pi \mathrm{c}=0 \rightarrow \sigma^{*} \mathrm{C7C8}$ & $\mathrm{G}_{2 / 3}-\mathrm{G}_{1}$ \\
\hline inward & 29.6 & 50.0 & 54.7 & 40.7 & 1.5 & -2.9 \\
\hline outward & 28.5 & 42.7 & 47.2 & 23.2 & 6.5 & -6.1 \\
\hline
\end{tabular}


Other significant NBO interactions in the inward and outward opening TS structures for $\mathbf{9}$ and $\mathbf{1 0}$ are collected in Tables 11 and 12 , respectively. The originally anticipated $\pi_{\mathrm{c} 1 \mathrm{C} 2} \rightarrow \sigma^{*}{ }_{\mathrm{c} 3 \mathrm{c} 4}$ and $\pi_{\mathrm{c5} 56} \rightarrow \sigma^{*}{ }_{\mathrm{c} 3 \mathrm{C} 4}$ interactions are absent here as well.

Table 11. Other significant NBO interactions $(\mathrm{kcal} / \mathrm{mol})$ present in the inward and outward opening TS structures of anti-7-formyl-3,4-cyclopropanobicyclo[4.2.0]octan-1,5-diene, 9

\begin{tabular}{|l|l|l|l|l|l|l|}
\hline TS & $\pi_{\mathrm{C} 1 \mathrm{C} 2} \rightarrow \sigma^{*}{ }_{\mathrm{C} 3 \mathrm{C} 4}$ & $\pi_{\mathrm{C} 5 \mathrm{C} 6} \rightarrow \sigma^{*}{ }_{\mathrm{C} 3 \mathrm{C} 4}$ & $\pi_{\mathrm{C} 1 \mathrm{C} 6} \rightarrow \pi_{\mathrm{C} 2 \mathrm{C} 3}$ & $\pi_{\mathrm{C} 2 \mathrm{C} 3} \rightarrow \pi_{\mathrm{C} 1 \mathrm{C} 6}$ & $\pi_{\mathrm{C} 1 \mathrm{C} 6} \rightarrow \pi^{*}{ }_{\mathrm{C} 4 \mathrm{C} 5}$ & $\pi_{\mathrm{C} 4 \mathrm{C5}} \rightarrow \pi^{*}{ }_{\mathrm{C} 1 \mathrm{C} 6}$ \\
\hline inward & 0.0 & 0.0 & 14.0 & 12.8 & 12.8 & 09.6 \\
\hline outward & 0.0 & 0.0 & 12.1 & 10.8 & 14.3 & 16.1 \\
\hline
\end{tabular}

Table 12. Other significant NBO interactions $(\mathrm{kcal} / \mathrm{mol})$ present in the inward and outward opening TS structures of syn-7-formyl-3,4-cyclopropanobicyclo[4.2.0]octan-1,5-diene, 10

\begin{tabular}{|l|l|l|l|l|l|l|}
\hline TS & $\pi_{\mathrm{C} 1 \mathrm{C} 2} \rightarrow \sigma^{*}{ }_{\mathrm{C} 3 \mathrm{C} 4}$ & $\pi_{\mathrm{C} 5 \mathrm{C} 6} \rightarrow \sigma^{*}{ }_{\mathrm{C} 3 \mathrm{C} 4}$ & $\pi_{\mathrm{C} 1 \mathrm{C} 6} \rightarrow \pi_{\mathrm{C} 2 \mathrm{C} 3}$ & $\pi_{\mathrm{C} 2 \mathrm{C} 3} \rightarrow \pi_{\mathrm{C} 1 \mathrm{C} 6}$ & $\pi_{\mathrm{C} 1 \mathrm{C} 6} \rightarrow \pi^{*}{ }_{\mathrm{C} 4 \mathrm{C} 5}$ & $\pi_{\mathrm{C} 4 \mathrm{C5}} \rightarrow \pi^{*}{ }_{\mathrm{C} 1 \mathrm{C6}}$ \\
\hline inward & 0.0 & 0.0 & 12.1 & 09.9 & 13.4 & 16.9 \\
\hline outward & 0.0 & 0.0 & 13.9 & 18.7 & 13.7 & 09.8 \\
\hline
\end{tabular}

Encouraged from the results for $\mathbf{9}$ and $\mathbf{1 0}$, we next studied the corresponding epoxy derivatives $\mathbf{1 1}$ and 12. The activation free energies and torquo-controlling NBO interactions in the inward and outward openings of 11 and 12 are collected in Tables 13 and 14, respectively. While 11 is torquo-neutral like $\mathbf{9 ,} \mathbf{1 2}$ is selective to outward opening like $\mathbf{1 0}$ from the differential activation energies. Like $\mathbf{9}$ and $\mathbf{1 0}$, these substrates are also inward selective from the torquo-controlling $\sigma_{\mathrm{C7C8}} \rightarrow \pi^{*}{ }_{\mathrm{c}=\mathrm{O}}$ and $\pi_{\mathrm{C}=\mathrm{O}} \rightarrow \sigma^{*}{ }_{\mathrm{C} 7 \mathrm{C} 8}$ interactions. Thus, 11 and 12 are also good candidates to weigh the validity of the differential activation energy approach over the NBO approach. The other significant NBO interactions are given in Tables 15 and 16. The consistency in the absence of $\pi_{\mathrm{C} 1 \mathrm{C} 2} \rightarrow \sigma^{*}{ }_{\mathrm{c3} 34}$ and $\pi_{\mathrm{C5} 6} \rightarrow \sigma^{*}{ }_{\mathrm{c3c} 4}$ interactions is retained.

Table 13. Gibbs' free energy of activation $\left(\Delta \mathrm{G}^{\ddagger}\right)$ and important NBO interactions $(\mathrm{kcal} / \mathrm{mol})$ for the inward and outward openings of anti-7-formyl-3,4-epoxy-bicyclo[4.2.0]octan-1,5-diene, 11

11<smiles>C[C@]12C=C3C[C](C=O)C3=C[C@@H]1O2</smiles>

\begin{tabular}{|c|c|c|c|c|c|c|}
\hline TS & $\Delta \mathrm{G}^{\ddagger}$ & $\pi_{\mathrm{C} 1 \mathrm{C} 6} \rightarrow \sigma^{*}{ }_{\mathrm{C} 7 \mathrm{C} 8}$ & $\sigma_{\mathrm{C} 7 \mathrm{C} 8} \longrightarrow \pi^{*}{ }_{\mathrm{C} 1 \mathrm{C} 6}$ & $\sigma_{\mathrm{C} 7 \mathrm{C} 8} \longrightarrow \pi^{*} \mathrm{C}=\mathrm{O}$ & $\pi_{\mathrm{C}=0} \rightarrow \sigma^{*}{ }_{\mathrm{C} 7 \mathrm{C} 8}$ & $\mathrm{G}_{2 / 3}-\mathrm{G}_{1}$ \\
\hline inward & 32.5 & 44.9 & 49.0 & 39.9 & 1.3 & -07.7 \\
\hline outward & 32.5 & 40.3 & 45.7 & 22.3 & 6.5 & -11.6 \\
\hline
\end{tabular}


Table 14. Gibbs' free energy of activation $\left(\triangle \mathrm{G}^{\ddagger}\right)$ and important NBO interactions $(\mathrm{kcal} / \mathrm{mol})$ for the inward and outward openings of syn-7-formyl-3,4-epoxy-bicyclo[4.2.0]octan-1,5-diene, 12

12

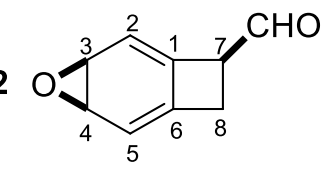

\begin{tabular}{|l|l|l|l|l|l|l|}
\hline TS & $\triangle \mathrm{G}^{\ddagger}$ & $\pi \mathrm{C} 1 \mathrm{C6} \rightarrow \sigma^{*} \mathrm{C7C8}$ & $\sigma \mathrm{c7C8} \rightarrow \pi^{*}{ }_{\mathrm{C} 1 \mathrm{C} 6}$ & $\sigma \mathrm{c7C8} \rightarrow \pi^{*} \mathrm{c}=\mathrm{O}$ & $\pi \mathrm{C}=0 \rightarrow \sigma^{*} \mathrm{C7C8}$ & $\mathrm{G}_{2 / 3}-\mathrm{G}_{1}$ \\
\hline inward & 33.8 & 43.6 & 48.1 & 38.7 & 1.4 & -7.8 \\
\hline outward & 32.1 & 39.1 & 44.0 & 22.0 & 6.4 & -11.7 \\
\hline
\end{tabular}

Table 15. Other significant NBO interactions $(\mathrm{kcal} / \mathrm{mol})$ present in the inward and outward opening TS structures of anti-7-formyl-3,4-epoxy-bicyclo[4.2.0]octan-1,5-diene, 11

\begin{tabular}{|l|l|l|l|l|l|l|}
\hline TS & $\pi_{\mathrm{C} 1 \mathrm{C} 2} \rightarrow \sigma_{\mathrm{C} 3 \mathrm{C} 4}$ & $\pi_{\mathrm{C} 5 \mathrm{C} 6} \rightarrow \sigma_{\mathrm{C} 3 \mathrm{C} 4}$ & $\pi_{\mathrm{C} 1 \mathrm{C} 6} \rightarrow \pi_{\mathrm{C} 2 \mathrm{C} 3}$ & $\pi_{\mathrm{C} 2 \mathrm{C} 3} \rightarrow \pi_{\mathrm{C} 1 \mathrm{C} 6}$ & $\pi_{\mathrm{C} 1 \mathrm{C} 6} \rightarrow \pi_{\mathrm{C} 4 \mathrm{C} 5}$ & $\pi_{\mathrm{C} 4 \mathrm{C} 5} \rightarrow \pi_{\mathrm{C} 1 \mathrm{C} 6}$ \\
\hline inward & 0.0 & 0.0 & 13.6 & 16.8 & 12.8 & 08.6 \\
\hline outward & 0.0 & 0.0 & 11.8 & 09.7 & 13.7 & 14.1 \\
\hline
\end{tabular}

Table 16. Other significant NBO interactions $(\mathrm{kcal} / \mathrm{mol})$ present in the inward and outward opening TS structures of syn-7-formyl-3,4-epoxy-bicyclo[4.2.0]octan-1,5-diene, 12

\begin{tabular}{|l|l|l|l|l|l|l|}
\hline TS & $\pi_{\mathrm{C} 1 \mathrm{C} 2} \rightarrow \sigma^{*}{ }_{\mathrm{C} 3 \mathrm{C} 4}$ & $\pi_{\mathrm{C} 5 \mathrm{C} 6} \rightarrow \sigma^{*}{ }_{\mathrm{C} 3 \mathrm{C} 4}$ & $\pi_{\mathrm{C} 1 \mathrm{C} 6} \rightarrow \pi_{\mathrm{C} 2 \mathrm{C} 3}$ & $\pi_{\mathrm{C} 2 \mathrm{C} 3} \rightarrow \pi_{\mathrm{C} 1 \mathrm{C} 6}$ & $\pi_{\mathrm{C} 1 \mathrm{C} 6} \rightarrow \pi_{\mathrm{C} 4 \mathrm{C} 5}$ & $\pi_{\mathrm{C} 4 \mathrm{C5}} \rightarrow \pi_{\mathrm{C} 1 \mathrm{C} 6}$ \\
\hline inward & 0.0 & 0.0 & 12.2 & 09.6 & 13.0 & 15.6 \\
\hline outward & 0.0 & 0.0 & 13.5 & 17.2 & 13.4 & 08.9 \\
\hline
\end{tabular}

\section{CONCLUSIONS}

From the studies of 3,4-cyclopropano-7-formyl-bicyclo[4.2.0]octan-1,5-diene and also 3,4-epoxy-7formyl-bicyclo[4.2.0]octan-1,5-diene and using the differential activation energy approach, we have shown that the strong inward opening tendency of the formyl group is either counter balanced to a level that the reaction turns torquo-neutral or it rotates outward, depending upon the anti or syn relationship of the small ring system with the formyl substituent, respectively. However, all along, the NBO interaction approach predicts inward selectivity. Thus, the molecules 9-12 can be used as excellent test substrates to determine the validity of one approach over the other.

The strong stereochemical effect of the remote small ring unit on the torquoselectivity of conrotatory ring opening is demonstrated for the first time. The display of torquo-neutral behaviour to reversal in the trend of normally observed torquoselectivity is interesting. 


\section{ASSOCIATED CONTENT}

\section{Supporting Information}

Coordinates of the geometries, Gibbs' free energies, Gibbs' activation free energies, and imaginary frequencies of the transition state structures.

\section{ORCID}

Veejendra K. Yadav: 0000-0001-8294-0677

\section{Notes}

The author declares no conflict of interest.

\section{ACKNOWLEDGEMENTS}

The author acknowledges allocation of time on HPC series of supercomputers by the Computer Centre, Indian Institute of Technology Kanpur.

\section{REFERENCES}

1. An NBO-TS predictive approach for torquoselectivity of ring opening in 3-substituted cyclobutenes, A. Yadav, D. L. V. K. Prasad and V. K. Yadav (2017): ChemRxiv. Preprint. https://doi.org/10.26434/chemrxiv.5743305.v1

2. C. W. Jefford, G. Bernardinelli, Y. Wang, D. C. Spellmeyer, A. Buda and K.N. Houk, Torquoselectivity in the Electrocyclic Conversion of Benzocyclobutenes to o-Xylylenes, J. Am. Chem. Soc. 1992, 114, 1157-1165.

3. S. Niwayama, E. A. Kallel, D. C. Spellmeyer, C. Sheu and K. N. Houk, Substituent Effects on Rates and Stereoselectivities of Conrotatory Electrocyclic Reactions of Cyclobutenes. A Theoretical Study, J. Org. Chem. 1996, 61, 2813-2825.

4. J. A. Berson, The Overlap Component of the Stereoelectronic Factor. Remote Control of Stereogenicity Transfer through the Anisotropic Influence of a Ring, Acc. Chem. Res. 1991, 24, 215222.

5. K. Rudolf, D. C. Spellmeyer, K. N. Houk, Prediction and Experimental Verification of the Stereoselective Electrocyclization of 3-Formylcyclobutene J. Org. Chem. 1987, 52, 3708-3710.

6. Y. Zhao, D. G. Truhlar Theor. Chem. Acc. 2008, 120, 215. 
7. A. E. Reed, L. A. Curtiss, F. Weinhold Chem. Rev. 1988, 88, 899.

8. Gaussian 09, Revision B.01, M. J. Frisch, G. W. Trucks, H. B. Schlegel, G. E. Scuseria, M. A. Robb, J. R. Cheeseman, G. Scalmani, V. Barone, B. Mennucci, G. A. Petersson, H. Nakatsuji, M. Caricato, X. Li, H. P. Hratchian, A. F. Izmaylov, J. Bloino, G. Zheng, J. L. Sonnenberg, M. Hada, M. Ehara, K. Toyota, R. Fukuda, J. Hasegawa, M. Ishida, T. Nakajima, Y. Honda, O. Kitao, H. Nakai, T. Vreven, J. A. Montgomery, Jr., J. E. Peralta, F. Ogliaro, M. Bearpark, J. J. Heyd, E. Brothers, K. N. Kudin, V. N. Staroverov, T. Keith, R. Kobayashi, J. Normand, K. Raghavachari, A. Rendell, J. C. Burant, S. S. Iyengar, J. Tomasi, M. Cossi, N. Rega, J. M. Millam, M. Klene, J. E. Knox, J. B. Cross, V. Bakken, C. Adamo, J. Jaramillo, R. Gomperts, R. E. Stratmann, O. Yazyev, A. J. Austin, R. Cammi, C. Pomelli, J. W. Ochterski, R. L. Martin, K. Morokuma, V. G. Zakrzewski, G. A. Voth, P. Salvador, J. J. Dannenberg, S. Dapprich, A. D. Daniels, O. Farkas, J. B. Foresman, J. V. Ortiz, J. Cioslowski, D. J. Fox, Gaussian, Inc., Wallingford CT, 2010.

9. Ethylene oxide has less ring strain than cyclopropane for the fact that the $\mathrm{C}-\mathrm{O}-\mathrm{C}$ angle has less strain due to its relaxed value at $104.5^{\circ}$, compared to the relaxed $C-C-C$ angle of $109.4^{\circ}$. Also see, $M$. S. Gordon, Ring Strain in Cyclopropane, Cyclopropene, Silacyclopropane, and Silacyclopropene, J. Am. Chem. Soc. 1980, 102, 7419-7422. 


\section{For Table of Content}

The strong inward opening tendency of the formyl group in 3,4-cyclopropano-7-formylbicyclo[4.2.0]octan-1,5-diene and also 3,4-epoxy-7-formyl-bicyclo[4.2.0]octan-1,5-diene is either counter balanced to a level that the reaction turns torquo-neutral or it rotates outward, depending upon the stereo-relationship of the small ring unit with the formyl substituent.

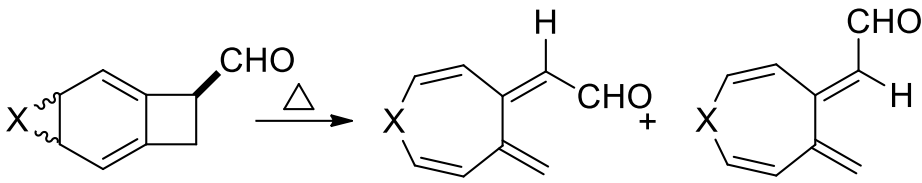
$\mathrm{X}=\mathrm{CH}_{2}, \mathrm{O}$ 